\title{
Los "nuevos lugares" de la ciudad entre condiciones territoriales, mecanismos de visibilidad/invisibilidad y procesos de disputa por el reconocimiento socio-político: repensando las ciudades contemporáneas desde la perspectiva de Buenos Aires
}

\section{The "new places" in the city among the territorial conditions, mechanisms of visibility/invisibility and disputes over the socio-political recognition: rethinking contemporary cities from the perspective of Buenos Aires}

\author{
Mónica Lacarrieu \\ monica.lacarrieu@gmail.com \\ Universidad de Buenos Aires
}

\begin{abstract}
Resumen: En los últimos años, las ciudades han sido objeto de políticas urbanas relacionadas a los procesos de recualificación cultural, al mismo tiempo en que han sido analizadas desde una perspectiva fragmentaria. Desde esta visión se ha fortalecido una lectura territorial de la ciudad contemporánea, desde la cual tiende a pensarse que los sujetos y grupos sociales se constituyen en el seno de "enclaves" condicionados por el territorio. Es nuestro objetivo en este artículo, discutir y reflexionar críticamente sobre esta perspectiva, particularmente sobre la fragmentación urbana, y desde una idea asociada a "nuevas políticas de lugares". Partiendo de que el territorio solo es una condición en la producción socio-espacial de la ciudad y que el mismo es disputado en pos de procesos de negociación, visibilidad y reconocimiento público por parte de diversos grupos sociales, debatiremos sobre la idea de anclaje territorial, de sociabilidad determinada por el territorio, sin por ello dejar de lado los procesos de segregación que se activan en ese contexto.
\end{abstract}

Palavras clave: Anclajes territoriales. Políticas de lugares. Buenos Aires/ Argentina.

Resumo: Nos últimos anos, as cidades têm sido objeto de políticas urbanas relacionadas aos processos de requalificação cultural, ao mesmo tempo em que têm sido analisadas por uma perspectiva fragmentada. A partir desta visão, se tem fortalecido uma leitura territorial da cidade contemporânea, na qual se tende a pensar que os sujeitos e grupos sociais se constituem em um sinal de «enclaves» condicionados pelo território. O objetivo deste artigo é discutir e refletir criticamente sob esta perspectiva, particularmente sobre a fragmentação urbana, e a partir dessa ideia, associar «novas políticas de lugares». Parte-se do princípio de que o território é apenas uma condição na produção socioespacial da cidade e que ele mesmo é disputado pelos processos de negociação, visibilidade e reconhecimento público por parte de diversos grupos sociais. Debate-se a ideia de enclave territorial e de sociabilidade determinada pelo território, sem com isso deixar de lado os processos de segregação que se ativam nesse contexto.

Palavras-chave: Enclaves territoriais. Políticas de lugares. Buenos Aires/Argentina. 


\begin{abstract}
Over the past years, cities have been subject to urban policies related to the processes of cultural regeneration, and at the same time they have been analyzed by a fragmented perspective. From this point of view, what has strengthened itself is a certain territorial reading on the contemporary city, in which one tends to think that individuals and social groups constitute a sign of "enclaves" conditioned by the territory. The aim of this paper is to discuss and critically reflect on this perspective, particularly on urban fragmentation, and starting from that idea, we are going to involve "new politics of place." It is assumed that that the territory is only one condition in the production of social spaces and that the territory itself is disputed through processes of negotiation, visibility and public recognition by various social groups. The idea of territorial enclave and sociability determined by the territory is discussed, without however leaving aside the segregation processes that are activated in this context.
\end{abstract}

Keywords: Territorial enclaves. Place policies. Buenos Aires/Argentina.

\title{
1 INTRODUCCIÓN
}

La desindustrialización que tomó cuerpo hacia la década de los `70 en las ciudades del denominado Primer Mundo y se intensificó en los años '90 en las grandes y medianas ciudades de América Latina; es el contexto en el que la cultura se volvió el recurso por excelencia no solo para la resolución de problemas socio-económicos, sino también como estrategia para el desarrollo de proyectos de transformación urbana. Tales proyectos de planificación, así como los usos de la cultura en relación a los mismos, se han propuesto como antídotos necesarios a la crisis urbana. En otras palabras, las patologías urbanas, así caracterizadas en relación a la emergencia de la industrialización, han permanecido en la mirada de analistas y urbanistas. La diferencia radica en los nuevos tratamientos dados a las mismas.

La aparente resolución de los problemas urbanos a través de operaciones estratégicas en las que la cultura, el diseño y la estética son principios estructuradores de la denominada "ciudad creativa", se ha consensuado como gestión idealista de lo urbano, sin embargo también a contrapelo de dicha visión, pues simultáneamente ha dado lugar a la contracara del modelo, también observada como patológica: nos referimos a la fragmentación urbana. Si bien la visión asociada a la fragmentación urbana aparece como un "dato natural" (fundado en una perspectiva espacialista desde la cual es legítimo discutir sobre muros que separan una villa de emergencia de un barrio de mayor nivel socioeconómico) y, por ende, disociado de propuestas y planes urbanísticos; son precisamente los proyectos estratégicos los que contribuyen en el diseño de "fragmentos" mediante operaciones microquirúrgicas que actúan sobre lugares circunscriptos y cristalizados en tanto espacios que, desde la recualificación, son convertidos - al decir de Jérôme Monnet (1996, p.189-204) - en "lugares fuera de lo común" taxativamente distantes de aquellos relegados de dichas operatorias.

Hace ya varios años el sociólogo francés Jacques Donzelot (2004) hacía referencia a las transformaciones que se habían producido en la París contemporánea. En aquellos 
textos, el autor refería, por un lado, al surgimiento de una "lógica de la separación" que, de acuerdo a su perspectiva, volvió defectuosa la unidad relativa de la sociedad urbana; por el otro, destacaba el cambio que se produjo entre la ciudad industrial en la que la cuestión social se definía desde los problemas sociales, y la ciudad desindustrializada, definida por una "nueva cuestión social" en la que, según el autor, no es la sociedad, sino el barrio lo que se vuelve y produce problema(s). Aunque las tres velocidades de las que habló Donzelot - relegación, periurbanización y gentrificación - no solo se definen espacialmente, hay en su análisis un sesgo territorial-espacialista que contribuye en la concepción fragmentaria de las ciudades contemporáneas.

Las ciudades latinoamericanas no han escapado a esta visión en la que prima una mirada patológica basada en la fragmentación. La lógica de la separación relacionada con la materialización de fragmentos espaciales con efectos sobre la denominada "desolidarización" (DONZELOT, 2004; BÉNIT et al., 2007), sería consecuencia, al menos, de dos asuntos, uno más genérico y otro más específico: los cambios en los modos de producción de la ciudad y la crisis de los espacios públicos urbanos (BÉNIT et al, Op.cit.). Como bien ha destacado Ángela Giglia (2000), las indagaciones articuladas en torno a la fragmentación coinciden en describir a las ciudades actuales a partir de un par de rasgos fundamentales: por un lado, la crisis y desaparición del espacio público como ámbito de encuentro y convivencia entre sujetos heterogéneos (con la subsiguiente proliferación de espacios privados/cerrados, vigilados y de acceso restringido) y, por otro lado, la conformación de universos sociales homogéneos que - a modo de compartimentos estancos - reducen la sociabilidad a un reconocimiento entre pares. Es desde esta lógica en que consideramos que los análisis sobre las ciudades actuales, realizados desde las ciencias sociales y el urbanismo, confluyen en una perspectiva que no solo vacía las nociones de contenidos problemáticos - por ejemplo la de fragmentación por relación a la de segregación -, sino que fundamentalmente despolitiza la producción de lo urbano. La división, no solo elude el carácter relacional de la ciudad (AGIER, 1999), sino que además enfatiza el fortalecimiento de "mosaicos" y niega las desigualdades como valor estructurante (CALDEIRA, 2010, p.118).

En relación a este contexto hay dos asuntos que se presentan como problemáticos. Por un lado, como en la década de los '90 lo planteara Milton Santos (1996, p.16, n/ traducción), se ha producido un "retorno del territorio", sin embargo, "con una noción... heredada de la Modernidad". La visión de Donzelot que muestra al barrio como problema, alimenta la versión fragmentada de la ciudad y se vincula a la idea del territorio como tal, en estado puro y de fijación, desgajado de los usos que se producen sobre el mismo. De hecho, esta visión más espacialista que social ha contribuido en la perspectiva del enclave-guetto a través de la cual, en los últimos años, se ha tendido a pensar y analizar las ciudades contemporáneas. Cabe señalar la aparente contradicción que, en este sentido, atraviesa lo urbano: en un mundo en que el territorio se ha observado diluido en un contexto de transnacionalización, y el mismo se ve permeado por la movilidad antes que por la fijación, la vuelta del territorio en el pensamiento sobre las ciudades se produce de la mano de la modernidad -como hemos señalado destacó Santos-. Por el otro, la visión 
territorialista se observa como condición y "variable de ajuste en las políticas de gestión de la diversidad" (GIBAND, 2011, p.12, n/traducción). Es decir que al mismo tiempo en que retorna el territorio, también se manifiesta la diversidad cultural en su concepción más relativista. La fragmentación urbana emerge en la articulación mecánica que se produciría entre el sentido territorial y el cultural. De allí que la constitución urbana entre "mosaicos" - en su visión particularista/fragmentaria, o entre enclaves-guettos - en una perspectiva ambigua que se constituye entre la (auto)discriminación y la afirmación positiva de ciertos grupos, paraliza y cristaliza el sentido complejo y conflictivo de la conformación urbana contemporánea. Efectivamente, el problema de la diversidad en términos de coexistencia de la diferencia que ha sido vista como patología de la ciudad moderna, permanece como cuestión a resolver. En ese sentido, la clave está centrada en el asunto de la igualdad - del mismo modo en que fue una cuestión crucial en la ciudad de la industria, solo que en la contemporaneidad se coloca el acento en la diversidad y su anclaje territorial. Atravesada o no por criterios de etnicidad, la problemática se analiza tanto positiva como negativamente: en torno del "vivir en conjunto" en tanto valor equivalente de la igualdad - basada en rasgos de afinidad ${ }^{1}$ - o de las "minorías" que se fijan en enclaves, ya no miradas como sectores homogéneos de afirmación positiva, sino en relación al "miedo al pequeño número" (APPADURAI, 2009). Como señala Giband (2011), el territorio es el receptáculo de esa diversidad, que de categoría social se ha vuelto categoría espacial teñida de culturalismo.

Esta perspectiva asociada a la política y gestión de lo urbano - si bien contribuye en una visión frecuentemente des-politizada, en la que se producen recurrentes procesos vinculados a la denominada recualificación urbana, ha contribuido y contribuye aún en una mirada de-socializada y des-problematizada de la ciudad tanto asociada a la idea de la fragmentación como a la de la ciudad de la diversidad.

Comenzar por estas apreciaciones encuentra sentido en la propuesta que subyace a este texto. En línea con una relativa problematización de la condición espacio-cultural - en ocasiones deterministas, en torno de la cual se constituyen las ciudades actuales, nos interesa analizar críticamente los procesos de negociación y/o disputa que tensan los usos y apropiaciones de los lugares. Discutiendo con la visión espacial y culturalista que tiende a construir en planos de igualdad los diferentes territorios y agrupamientos sociales, es nuestro objetivo volver sobre las prácticas sociales que se constituyen en la lógica de diferentes actores sociales, desde las cuales se co-producen compleja y conflictivamente sistemas y políticas de lugares que trascienden la condición territorial - aunque la misma esté involucrada. "Tener espacio" o disputar el espacio implica redefinir su sentido, es decir pensarlo como un recurso, "como fuente de poderes" en torno del cual se procesan modalidades diferentes y desiguales relacionadas al control sobre sus usos y apropiaciones sociales (SIGNORELLI, 1999, p.53 y 56). La cuestión

1 El denominado "urbanismo afinitario" destacado por Donzelot en relación a asentamientos periurbanos (los nuevos y no tan nuevos barrios cerrados que han proliferado en nuestras ciudades), pero que sin duda podría ser extrapolable a los diferentes "entre sí" con que el mismo autor define las formas de agregación social que prevalecen en espacios de la relegación o incluso de la gentrificación, habla de esa búsqueda de homogeneidad como mecanismo de separación y como respuesta conductista del barrio como problema urbano. 
de la "microterritorialización", tanto en la perspectiva de la fragmentación como de la diversidad, consideramos que no solo provoca una visión homogénea, sin desniveles, ambigüedades, contradicciones, sino que también elude los procesos de intercambios e interacciones que se producen entre negociaciones, conflictos y disputas en pos de la co-producción política de lo urbano. En sintonía con la propuesta de este número temático, nos interesa volver sobre los procesos de interacciones/intercambios socio-culturales desplegados por grupos sociales en contextos urbanos producidos por el poder público/ privado, no obstante, colocando en primer plano una reflexión crítica sobre el rol del territorio en las negociaciones y/o disputas por el lugar ${ }^{2}$ y sobre todo en las modalidades y mecanismos de segregación social. Este asunto será analizado en torno de procesos y situaciones empíricas que tienen lugar en la ciudad de Buenos Aires, Argentina ${ }^{3}$.

\section{2 “CULTURA SIN AUTOR": CLAVES PARA REFLEXIONAR CRÍTICAMENTE SOBRE LAS NUEVAS “POLÍTICAS DE LUGARES” RECUALIFICADOS}

Los procesos en los que la cultura, el diseño y la estética son vectores de la conformación de los espacios urbanos contemporáneos, se constituyen en torno de una territorialidad explícita - en la misma se subsumen otros territorios legitimados como tales, desde la cual se invisibilizan otras territorialidades y las prácticas sociales que negocian y/o disputan tanto esa territorialidad visible como las ocultas.

Como hemos señalado al comienzo, estas nuevas formas de tratar los espacios de la ciudad se producen en una visión territorial-espacialista. En tanto las palabras no son neutrales, cuando los gobiernos, los gestores y planificadores, o los propios académicos hablamos de intervenciones culturales urbanas, estamos apelando a un modelo que se plantea, por un lado, como desterritorializado, pensando la desterritorialización como la forma hegemónica por excelencia para representar la globalización (MATO, 2003). Estas intervenciones se producen bajo la visión naturalizada en torno de una potente geografía imaginada ligada a la desterritorialización a-espacial (MASSEY, 2008). En la

2 En este texto retomaremos la noción de lugar como concepto mas completo y/o articulador complejo del espacio, los discursos sobre el mismo y las conflictivas prácticas sociales de los diferentes y desiguales actores involucrados con el mismo.

3 Las referencias empíricas de las cuales se nutre este texto son el resultado de investigaciones desarrolladas en el marco de la investigación individual implementada en el contexto del CONICET (Consejo Nacional de Investigaciones Científicas y Tecnológicas) y de la investigación colectiva llevada adelante en el contexto de Proyectos de Investigación Plurianual (PIP) bajo mi dirección, financiados por el CONICET, a los que se agregan el Proyecto FONCYT financiado por la Agencia Nacional de Promoción Científica y Tecnológica (finalizado en 2010 bajo mi dirección). La falta de espacio no permite desarrollar características del trabajo y proceso de investigación, no obstante, nos interesa resaltar que el mismo ha sido desenvuelto en torno de una metodología de carácter cualitativo bajo la perspectiva antropológica. Los resultados parciales que aquí se retoman - en forma generalista o particularista- se desprenden del trabajo de campo que realizamos en barrios de la ciudad de Buenos Aires como Puerto Madero, el centro histórico de la ciudad (San Telmo), La Boca (barrio considerado "típico" de esta urbe), Parque Patricios, todos ellos en el sur de Buenos Aires, a los que se agregan el "Barrio Chino" (barrio "inventado" por agrupaciones de chinos en términos genéricos, en el barrio de Belgrano), el Abasto (zona recortada del barrio de Balvanera donde se ha procurado un proceso de recualificación incompleto) y en la actualidad la Avenida de Mayo en relación al programa "Buenos Aires Celebra" y Floresta en la zona oeste de Buenos Aires. Debemos destacar que nuestras investigaciones no solo se recortan en pos de "unidades de estudio" territoriales (según el esquema de barrios), sino también observando y analizando los procesos socio-culturales desplegados por grupos sociales diversos, tanto definidos por su situación socio-económica (pobres urbanos) como étnico-cultural (afrodescendientes, chinos, bolivianos, entre otros).

4 Tomamos prestado el concepto de "cultura sin autor" desarrollado en el texto de Nicolás Bautes. 
perspectiva de la desterritorialización y globalización a-espacial, como señala Massey, "las multiplicidades esenciales de lo espacial son negadas", del mismo modo que las trayectorias específicas se ven como obstructivas. De allí, que la idea asociada a las intervenciones culturales urbanas responden a ese sentido de "inevitabilidad" (Op.cit. p.127) que implica un único camino posible que se imprime en las diferentes ciudades de nuestro continente. Desde el sentido global y a-espacial de estas propuestas (en el sentido dado por Massey que no se traduce en el fin del espacio, sino en pensar en un espacio que disuelve las fronteras, que se abre al infinito), la recualificación cultural aparenta ser un modelo homogéneo, único, extensible más allá de las fronteras, las temporalidades, los actores e intereses comprometidos. Una perspectiva que no solo omite las diferentes formas de re-cualificar en base a los múltiples contextos localizados, sino que autoriza la repetición, no solo en términos de la planificación urbana, sino incluso en relación a la producción académica que, más allá de matices, suele concluir genéricamente en que se trata de una tipología propia de la contemporaneidad y fundada en la "globalización desde arriba" (LINS RIBEIRO, 2006; SEGATO, 1997). Tal como lo plantea Massey (2008, p.129, n/traducción) en relación a la visión asociada al espacio global, los procesos de recualificación no son una descripción "real" de todos aquellos que se producen en distintas ciudades del mundo, sino más bien "una imagen a través de la cual el mundo está siendo hecho", o una imagen a través de la cual los procesos de recualificación están siendo desarrollados. En su contracara, como hemos visto en la introducción, son observados como modelos de planificación que operan sobre "fragmentos" desvinculados entre sí, exacerbados en su territorialidad, mirada desde la cual se omiten múltiples trayectorias y temporalidades a través de las cuales cada ciudad y dentro de cada una, cada espacio producido en ese sentido, responde de manera diferenciada.

Esta visión, en su doble arista, silencia la posibilidad de pensar estos procesos en tanto atravesados por su condición de transnacionalidad, en tanto condición compleja de producción transversalizada por las trayectorias y especificidades locales, que aunque constituida más allá de las fronteras nacionales, en torno de similitudes, sin quiebres, al mismo tiempo con fronteras, lleva a pensar que se producen entre diferencias, avances y retrocesos, y sobre todo entre relaciones de poder que contribuyen en procesos de desigualación. Si bien, en una primera instancia, tal como señala Smith (2006, p.67-68, n/ traducción) parece una cuestión de escala, la problemática asociada a las "estrategias de "regeneración" [constituidas] a través de las fronteras nacionales... inauguran estrategias de gentrificación trasnacional...". Proyectos que ya no tienen, aparentemente, un origen nacional, no obstante ello, fenómenos producidos en la transnacionalidad y contextuados en la situacionalidad de lo local. Aunque está claro que estos procesos en cada ciudad, deben ser mirados y comprendidos a la luz de las historias urbanas específicas o de los procesos históricos de conformación de cada una de ellas ${ }^{5}$, hay rasgos en común que parecen traspasar fronteras y apropiarse de espacios diversos.

5 Aunque la mayor parte de las ciudades latinoamericanas durante el siglo XX han respondido a planificaciones ligadas a la industrialización, no por ello las historias urbanas son homogéneas, como tampoco las historias que se escriben en la contemporaneidad son estrictamente globales. 
En este sentido, desde la mirada puesta en las ciudades contemporáneas, la cultura y el diseño se han aunado en la escenificación de procesos de recualificación cultural (el llamado "urbanismo escenográfico). En el caso de la ciudad de Buenos Aires, la primacía obtenida por estos procesos que comenzaron a visibilizarse en la década de los '90 obviamente este dato no es menor, e indica que las acciones urbanas llevadas a cabo bajo esta perspectiva, también responden a contextos socio-políticos - ha llevado a observar no solo la relevancia dada a la cultura, sino sobre todo a la tensión entre lo cultural y lo social: procesos que exaltan lo cultural, en tanto "riqueza" y devalúan y/o minimizan lo social, vinculado siempre a la "pobreza". La visión de la cultura como antídoto de las patologías urbanas retoma la concepción trascendente de la misma, y al mismo tiempo niega la incidencia de la cultura como una herramienta poderosa de control social. Si bien, en su expansión hacia otros niveles de la realidad social, parece perder ese lugar estrecho asociado a las artes cultas, su desparramamiento lleva en sí mismo cierta contradicción: la expansión es posible en la medida en que es visualizada como el recurso de atenuación, compensación y mejor administración de los conflictos y desigualdades socio-económicas y esto remite ineludiblemente a su papel de trascendencia, no obstante ello, es desde el mismo lugar en que la cultura es banalizada, diluyendo sus contenidos específicos entre tantos otros sin considerar que por ese camino la cultura se vuelve instrumento de poder.

Tamaso retomando a De Certeau (1996, p.195-196) nos habla del sentido restauracionista que impera en las iniciativas asociadas a la recualificación. Son los "objetos" o "cosas" en el sentido objetivista de la cultura o en la visión patrimonialista de lo tangible, y sobre todo su implantación como su restauración, componentes de relevancia en la imposición de nuevos valores en el pasaje hacia otros sistemas de prácticas y hacia el cambio de redes e interacciones de practicantes. Esta visión produce efectos cruciales para los sujetos y grupos, pues "la restauración de los objetos viene acompañada de una desapropiación de los sujetos", en suma, la recualificación dice más de los “objetos restaurados" que de los "beneficiarios de la restauración". Como señala Bautes (2010, p.359, n/traducción) la cultura en tanto recurso de la recualificación se traduce en "cultura sin autor", a contramano de los propios fines perseguidos por esta concepción, o sea por "fuera de preocupaciones sociales" y reflejada en "políticas económicas culturales". En este sentido, la cultura se convierte en un dispositivo material y simbólico que, adherido a monumentos, arte, patrimonio inmaterial, se torna “objeto de contemplación" y como señala De Certeau (1996) "sustrae a usuarios de lo que presenta a los observadores" (citado en TAMASO, 2006, p.4, n/traducción). Desde esta perspectiva, los procesos de recualificación son el producto de un "urbanismo escenográfico" (BORJA Y MUXI Op.cit.) que hace de la ciudad una especie de museo patrimonialista o de galería de arte donde las obras u objetos seleccionados son iluminados una vez en que se extraen de "su lugar" y por ende, son desapropiados de los sujetos productores o bien de los sujetos y grupos que usan y se apropian de los mismos. Los elementos recualificadores se transforman en dicho proceso y salen del espacio/tiempo cotidiano hacia un espacio/tiempo extra-cotidiano, desde los cuales se produce una imagen positiva. La territorialización de una imagen, construida en base a varias imágenes positivas de diferentes lugares excepcionalizados 
y diseñados, legitima una visión acerca de lo que una ciudad debe ser, como debe ser vivida, y asimismo, produce y promueve jerarquizaciones y límites acerca de lo propio y lo ajeno, lo permitido y lo prohibido, lo tolerable y lo intolerable, lo visible y lo invisible. ¿Hasta dónde esa imagen nos identifica como habitantes, transeúntes, residentes, etc. de la ciudad, en nuestro caso de Buenos Aires? ¿Quien se vuelve merecedor de esa imagen? ¿A quién construye como "nosotros" de la ciudad? La fijación de una imagen procura una idealización de la vida urbana, pero también la figura de un "ciudadano ideal". No necesariamente esta imagen como "marca" permite visibilizar identidades sociales $\mathrm{y}$ culturales que seguramente pueden generar resistencias a esas marcas (aunque en ocasiones también pueden ser funcionales de modo de competir y sentirse parte de la ciudad ideal).

En relación a estos nuevos procesos es necesario considerar algunos aspectos claves y estructuradores de los mismos. En primer lugar, ya no basta convivir en barrios, sino que además esos barrios y/o los lugares de los mismos deben ser "pintorescos", y el pintoresquismo no es algo que se logra fácilmente. No cualquier lugar - barrio, calle, pasaje etc. - cuenta con los componentes materiales y simbólicos necesarios para convertirse en pintoresco: ante todo hay que gestar un guión, o en palabras de De Certeau (1996), un "relato de viaje" que permita practicar el espacio entre hitos e íconos que lo hagan más bello, más exótico y al mismo tiempo más puro. Del "barrio" al "paisaje cultural" (ZUKIN, 1996) se produce esa transformación que modifica la conformación de las ciudades. La idea de "paisaje cultural" implica esa perspectiva del "arreglo espacial" y de impresión/condensación de símbolos que hacen "pintoresco/típico" el espacio en cuestión. En algunos espacios la idea de lo "pintoresco" es inventada en pos de este tipo de procesos, pero en otros, por ejemplo La Boca ${ }^{6}$, es posible que esa transformación sea el resultado de una readquisición de "accidentes de la historia" (COELHO, 2008). Las casas coloridas (conventillos) que han producido una imagen tradicional del lugar, no obstante producto de una invención cultural que se asumió originaria y con continuidad histórica, constituyen un buen ejemplo de reproducción cultural en torno de la cual se producen las recualificaciones ${ }^{7}$. Esta especialización se supone produce una ciudad más asociada al consumo que a la producción, más consensuada sin conflicto que vinculada a procesos de resistencia.

En segundo lugar, la recualificación opera en mayor grado sobre los espacios públicos que sobre el habitar, la habitabilidad y la vivienda - es decir que aunque se espera

6 La Boca es un barrio del sur de la ciudad de Buenos Aires ubicada en la vera del Riachuelo. Hacia allí se trasladaban los migrantes europeos que llegaban a esta ciudad entre fines del siglo XIX y principios del XX. A partir de los 50 y 60 de este siglo, hubo recambios de población, ingresando en el barrio migrantes de países limítrofes y del interior del país. En la actualidad es un barrio atractivo turísticamente en su paseo emblemático (Caminito) pero al mismo tiempo es un espacio pauperizado. La recualificación llevada adelante en el mismo ha hecho foco en Caminito y sus alrededores.

7 Los conventillos son casas colectivas que en su origen construyeron los primeros inmigrantes europeos. De chapa y madera, en los primeros tiempos fueron pintadas de colores llamativos, debido a dos cuestiones: 1) se dice que los migrantes tomaban los restos de pinturas de los barcos y con los mismos pintaban las casas, 2) la relevancia tomada por Quinquela Martín como artista plástico del lugar y en ese sentido, productor de obras ligadas al barrio, fue parte de la herencia colorida que se condensó en el Pasaje de Caminito. El conventillo, si bien vivienda, también se ha constituido como el bien simbólico por excelencia que, en torno de la recualificación, se ha transformado en museo temático, galería de arte, atelier, siempre pos desalojo de sus habitantes empobrecidos. Sin embargo, esta recualificación no ha podido cerrar en relación a todo el barrio y los numerosos conventillos que lo pueblan. 
que estas acciones con la cultura como recurso intervengan sobre lo social, normalmente esta esfera es relegada, incluso contribuyendo a la profundización de la pobreza, no solo por vía de la expulsión de población, sino también por vía del enmascaramiento de la segregación. La centralidad de los espacios públicos es un aspecto que se ha visto con claridad en la rehabilitación de Puerto Madero $^{8}$ - quienes planificaron este lugar desde el inicio, plantearon que esta forma de "limpieza" de los espacios públicos, implicaría "nuevos roces" entre las personas, es decir, la conformación de una "nueva urbanidad" basada en una moral urbana que, sin embargo, es selectiva. Pero incluso, la relación de este tipo procesos con el centro histórico, San Telmo, muestra cómo la relevancia dada a los espacios públicos ha sido crucial en la profundización de la segregación social. Por solo tomar un ejemplo, la construcción de un "paisaje cultural" en este lugar, produjo micro-paisajes centrales a la revalorización de los espacios públicos. El desalojo del ex Padelai (en su momento habitado por 300 familias) y su conversión en el Centro Cultural de España ${ }^{9}$ resulta un buen ejemplo de ese objetivo y al mismo tiempo, muestra las consecuencias de este cambio: por un lado, la idea de un centro cultural que traspase las fronteras de sus puertas, tome cuenta de la calle, y que incluso autorice el ingreso en pos de actividades que exceden la cultura en el sentido convencional del término; por el otro, su conversión ha contribuido en la devaluación de las necesidades de vivienda para los sectores populares, y la revalorización de la cultura en tanto rastro y huella urbana.

En tercer lugar, accionar sobre los espacios públicos implica generar una visión asociada a la contemplación y a la circulación, antes que a la apropiación social. Esta visión asociada a la contemplación consideramos que se asocia al supuesto según el cual la gestión pública actual focaliza su accionar, como hemos dicho, en la intervención sobre los espacios públicos antes que sobre la vivienda. En otras palabras, creemos que hoy resulta de mayor relevancia generar intervenciones que consideren el sujeto "en tránsito" (si bien "sujeto en tránsito" no se traduce en sujeto inmigrante), es decir que prioricen la circulación y movilidad antes que el sujeto residente, local y localizado. La contemplación que, según Gravari-Barbas (2005), puede traducirse en derecho a la mirada, un derecho que estaría vinculado al derecho a la belleza que postulara Amendola (2000). La mirada parece ser una cualidad y hasta un capital (en el sentido de Bourdieu) con el

8 Puerto Madero es el prototipo de estos procesos en la ciudad de Buenos Aires. Tomado como modelo para otras ciudades latinoamericanas, se produce en la década de los '90. La rehabilitación de los dockes abandonados, fue el origen del mismo, no obstante, en su desarrollo fue convirtiéndose en un nuevo barrio cubierto de torres y rascacielos. El objetivo de dicha recualificación fue la puesta en valor de "objetos" patrimoniales, no obstante, en pos de revalorizar los espacios públicos que se encontraban en franco deterioro, por ende intransitables para la población de la ciudad. La misma se convirtió en "modelo" debido a que era una zona deshabitada, donde no hubo necesidad de desalojos, ni expulsiones de población originaria.

9 El ex Padelai (Patronato de la Infancia en su origen) se encuentra emplazado en San Telmo, en el sur de la ciudad, donde la misma fue fundada. En los años ' 80 dicha institución ya no funcionaba como tal y fue ocupada por aproximadamente 300 familias que pasaron a habitarlo ilegalmente. En los '90 el nuevo intendente de la ciudad, Carlos Grosso, elaboró un convenio o acta de escritura según el cual concedía la posibilidad de continuar viviendo allí y convertirse en propietarios. En el año 2003 y luego de la crisis socio-económica de 2001-02, el Jefe de Gobierno de ese momento promovió el desalojo del mismo aduciendo que dicha escritura no tenía valor como tal. Luego de varios años en que el edificio fue cercado y vaciado y en que la justicia bloqueó su uso y comenzó a dirimir las posibilidades de convertirlo en Shopping o centro cultural, el mismo fue concesionado por muchos años al Centro Cultural España. Sus ex habitantes cada tanto regresan con sus reclamos de vivienda, sin embargo, el centro cultural se encuentra en funcionamiento y ha llevado adelante una política de promoción del mismo en el centro histórico, interpelando a los pobladores mediante una idea democratizadora del espacio público urbano. 
que cuentan más los expertos que quienes habitan los lugares. Desde la recualificación es posible observar este asunto: el centro histórico es más visible y comprensible para los patrimonialistas (que no solo son académicos o gestores del patrimonio, sino también grupos sociales que han adquirido ese capital) que para quienes procuran invisibilizarse en viviendas ocupadas ilegalmente o vinculadas a la pobreza. La primacía dada a la circulación y la contemplación está ligada a la visibilidad/invisibilidad en que se producen los espacios objeto de recualificación. Algunos autores ya mencionados, como Jordi Borja, han denominado este modelo como "urbanismo escenográfico" y otros, desde una perspectiva socio-antropológica, como procesos de "cultura sin autor" (BAUTES, 2010), pues son procesos que se constituyen desapropiando a los sujetos sociales locales (de los lugares) de sus historias, expresiones y bienes, generando espacios de contemplación donde el "derecho a la belleza" (una estética autorizada) produce una "inclusión parcial basada en la observación" -la idea del "derecho a la belleza" se produce a contrapelo del "derecho a la centralidad" para los sectores populares. Cabe destacar la relevancia que adquiere en esta redefinición de los lugares por vía de lo cultural, la imposición de la idea de belleza de acuerdo a cánones occidentalizados (AMENDOLA, 2000, p. 132-33) relacionados con cierta exigencia contemporánea de las ciudades: la impostación de la belleza como "un objeto de normalización positiva" o como "estética decretada" desde la cual se sanciona no solo la gama de colores con los cuales intervenir los lugares, sino sobre todo la elevación del espíritu, imaginando lugares sin conflicto y accesibles para todos, independientemente de los recursos materiales con que se cuente. Resulta de interés la apreciación que en el mismo sentido realiza Smith (Op.cit., p. 67) cuando señala que estas formas de ocupar el espacio son también intentos de "desestigmatización" de "zonas rojas" -"marcada en rojo" en los mapas de la ciudad por infringir moralidades legítimas.

Las aparentes ventajas de estos procesos, visualizadas en torno de una mayor democratización e inclusión social, tienden a distanciarse de lo social mediante intervenciones paisajísticas menos políticas y más segregacionistas, asimismo, son recursos que acaban autonomizándose y desconectándose del rol político y social que debieran implicar. Como hemos señalado, la visión de la cultura como recurso y su ampliación a la idea de creatividad supone mayor igualación y democratización e inclusión de los sujetos y grupos sociales en su diversidad. Pero la inclusión de los sujetos no garantiza su incorporación como sujetos históricos y productores de lo cultural, lo social y hasta de lo político.

En esta perspectiva, se crean y recrean "paisajes de poder" vinculados a la idea de consumo visual (ZUKIN, 1996). Más allá de la visión "paisajista" o territorial desde la cual se construye esta idea, la misma relega dos cuestiones a nuestro entender de importancia: por un lado, los procesos de producción y circulación de bienes y recursos materiales y simbólicos que involucrarían a todos los sujetos y grupos implicados en algún punto con la recualificación, asunto que al recargar las tintas sobre el consumo, deja a los sujetos en actitud de pasividad, pero particularmente a ciertos sectores sociales en relación a la "no producción" cultural, social y hasta política; por el otro, la inclusión de los "contra-usos" y/o "contra-paisajes". En el contexto del congreso Brasa realizado en Olinda, algunos 
especialistas del grupo de trabajo coordinado por Heitor Frúgoli, discutieron con la noción del "paisaje", incorporando la del "contra-paisaje". Dicha nominación construida en un cuadro de opuestos, se imaginaba por relación a los cambios que se habían producido en la Buenos Aires de la crisis socio-económica de 2001-02. No obstante, dicha noción nos interpelaba nuevamente con una visión espacialista y fragmentaria de la ciudad: la idea del "contra-paisaje" parecía reproducir por el antagónico "paisaje", nuevos "mosaicos" y espacios "arreglados" desde la crisis, colocados en el mismo nivel y al lado de aquellos recualificados por la vía del diseño y la estética. En una perspectiva mejorada, Proença Leite introdujo el concepto de "contra-usos", en tanto a partir de su estudio sobre la recualificación del Barrio histórico de Recife remarca la monotonía de esos paisajes ennoblecidos, al mismo tiempo en que es posible "repensar la construcción de esos lugares...a partir de los usos y contra-usos que se hacen de los espacios ennoblecidos" (2004, p. 213-214, n/traducción). El autor coloca en un plano similar los usos ligados a la recualificación que alteran los sentidos de los lugares intervenidos, y los contra-usos (por ende los contra-sentidos) que, de acuerdo a Proença Leite (Op.cit.), "contribuyen en una diversificación de los actuales sentidos de los lugares". Así como en la visión de los "contra-paisajes" se pierden los sujetos, en la de los "contra-usos" se diluyen las apropiaciones conflictivas de dichos sujetos sobre los mismos "paisajes".

\section{CUANDO EL TERRITORIO ES UN “LUGAR" NEGOCIADO Y/O DISPUTADO EN POS DE LA VISIBILIDAD Y EL RECONOCIMIENTO PÚBLICO}

“....se toma derecho por Balcarce hasta el parque Lezama y se llega el parque son unas cuantas cuadras. No el recorrido que suelen hacer a veces el día de las llamadas que hacen por el Gobierno que es al revés. Generalmente salen desde Pasaje San Lorenzo hacia el parque pero también van por otra calle. Salimos nosotros desde la Plaza a Parque Lezama y pasamos por el frente de la Iglesia que para nosotros tiene significado porque en otras épocas teníamos que pasar por ahí y estaba a lo mejor el cura dando misa y salía, le molestaba que pasáramos tocando los tambores, siempre era como una especie de discusión....bueno que la policía siempre viene en algún momento a no querer que se templen los tambores o que se salga tocando... eso es más o menos está bueno destacar que ese recorrido eh se genera porque es un recorrido que se hacía desde que estaban los puertos allá, vio la lomada de parque Lezama esa cosa así era todo agua antiguamente, entonces los puertos llegaban ahí desembarcaban y todo ese recorrido se generaba hasta la plaza Dorrego donde ahí eran subastados digamos las piezas, las piezas como se llamaban en aquel momento a las personas no? Que son de origen afro...ese recorrido simboliza eso, el recorrido mismo, este lugar es parte de la comunidad del candombe, es un lugar que está situado en una ubicación visible, no muy visible que es acá San Telmo. Entonces es un lugar que está ubicado estratégicamente para nosotros poder dar visibilidad a lo que no se ve, Entonces, este lugar está ubicado estratégicamente para dar visibilidad a todas esas, a toda esa comunidad, a todo ese potencial que está ahí y no es tan escuchado". (Testimonios del Movimiento Afrocultural en el Centro Cultural Plaza Defensa). 
Como hemos señalado, la visión de la cultura como recurso y su ampliación a la idea de creatividad supone mayor igualación y democratización e inclusión de los sujetos y grupos sociales en su diversidad. Si la ciudad industrial se entendía a través de un enfoque clasista, las ciudades actuales producen supuestas mezclas -bajo el prisma de la diversidad- que hacen que la definición de quienes se incluyen o se excluyen no sea definible solo por la clase social, sino también por quien puede o desea negociar con los recursos de la recualificación. Pero la inclusión de los sujetos no garantiza su incorporación como sujetos históricos/sociales y productores de cultura. Quienes son incorporados en los procesos comentados son las llamadas "clases creativas" que no son los grupos vulnerables socio-económicamente. La "clase creativa" - así denominada por Richard Florida (2002) - refiere a los "nuevos intermediarios culturales" (BOURDIEU, citado por BOVONE, 1997) o bien a quienes cuentan con capacidades de innovación en las que "la diversidad es en sí un vivero para la creatividad y la innovación y, por ende, para el desarrollo" (2008, p.51-52). No obstante, en afinidad con lo planteado por Yúdice (2008) para la ciudad de Miami, en Buenos Aires, como en otras ciudades, el reconocimiento de la diversidad es retórico, limitado a ciertos grupos, y a contrapelo de lo que se espera, promotor de tensiones entre lo social y lo cultural. Estos procesos en los que los usos de la cultura se observan como recursos para el crecimiento económico y el desarrollo, simultáneamente tienden a desintegrar la aparente integración social y cultural que se espera de los mismos. Veremos más adelante que esta visión es compleja, pues los procesos de recualificación enfatizan el rol de la diversidad en clave de "buen vivir"10, de convivencia local, de instrumento moral e incluso de "eufemización de las exclusiones" (TISSOT, 2011, p. 139, n/traducción), llevando desde esta perspectiva a su contracara, es decir a la producción aparente de "micro-enclaves" que quedan fragmentados/ desintegrados o bien que son expulsados de la integración idealizada. En esa línea de pensamiento es que Yúdice (Op.cit., p.52) observa el problema que crea la llegada de las "clases creativas" cuando señala que esta retórica no promueve el empleo entre los negros, que dicho discurso provoca discriminación entre los haitianos y obviamente entre los latinos blancos, entre otros grupos sociales. Dicho desde nuestro punto de vista, cambia la lectura que hoy se hace de la sociedad urbana, pero también las modalidades de inserción en los territorios urbanos.

La cultura como valor omnipresente no solo se inscribe en territorialidades centrales y patrimoniales, también se vuelve funcional en relación a nuevas definiciones de la pobreza urbana. La redefinición estratégica de la pobreza "como problema paisajístico (o ambiental)" (VAINER, 2000, p.82, n/traducción) vinculada a procesos que se desarrollan en favelas o villas de emergencia en Buenos Aires no hace más que reproducir una lógica universal donde la cultura es valorizada a fin de particularizar su existencia, pero "definida como "...vivencia en un territorio homogéneo, de "iguales"..." (BAUTES, Op.cit., p.161, n/traducción). Como señala el autor, la "estetización de la marginalidad", se convierte

10 Retomamos el concepto nativo del "buen vivir" y lo extrapolamos a la realidad urbana. El "buen vivir" se ha transnacionalizado como concepto propio de los pueblos originarios y vinculado a la diversidad como valor global. 
en un "recurso potencial de valorización territorial" (Op.cit., p.165, n/traducción), que aunque no siempre participa de manera uniforme, en ocasiones como la estudiada por Bautes, resulta "funcional" a los procesos descriptos. Es decir, que son procesos que pueden operar en asentamientos populares, como ha ocurrido recientemente en la villa 31 de Retiro de Buenos Aires ${ }^{11}$, donde la cultura a través de estéticas negociadas -el color a fin de producir "fachadismos" en las viviendas precarias- construye fronteras simbólicas, obviamente lábiles y flexibles que, al mismo tiempo, pueden reproducir y fortalecer fronteras materiales desde las cuales vuelve a interpelarse la "cultura villera" y el villero en tanto sujeto/objeto propio de la villa, extraíble de lo urbano. En la medida en que la diversidad cultural -valor inherente a la cultura como recurso- trasciende el espacio de representación o de exposición instalándose en el espacio de co-presencia ligado a la socialización y el encuentro/desencuentro con el “otro” (AMENDOLA, 2000, p. 278), “... la cultura [deviene] también en un lugar de conflicto explícito de las diferencias sociales y los miedos urbanos" (ZUKIN, 1996). La cultura no solo es herramienta de inclusión social aparente, sino también instrumento de control y poder. Ese control y poder no solo es propiedad de quienes cuentan con capital y recursos materiales y simbólicos, también puede ser apropiación de grupos y sujetos que, aunque distantes de lo cultural, se asocien a través de prácticas que hoy se asumen como culturales - fiestas, rituales y vestimentas.

Efectivamente se produce un vínculo entre el territorio y la cultura/diversidad cultural. No obstante, ese vínculo se construye en forma compleja y conflictiva: el territorio es objeto de negociaciones y disputas que tensan las relaciones, intercambios y prácticas sociales. Dicho vínculo parece lineal cuando se produce en términos de discurso y representación, mientras que se constituye entre prácticas de negociación y/o resistencia cuando se observa en relación a las situaciones de encuentro/desencuentro y a las prácticas sociales que se despliegan. La visión representacional asociada a la idea de la fragmentación apunta a una "diversidad incolora" que tanto puede verse como discriminación territorial positiva, así como negativa (GIBAND, 2011, p.12,n/traducción). Esta perspectiva del espacio urbano apunta sobre "micro-territorios" o "enclaves" en los que se constituyen espacios fronterizados de homogeneidad: resulta más simple la construcción del "enclave" villa - negativa o positivamente (cuando la diversidad cultural se colorea resulta funcional a la producción del "enclave") - que observar los procesos de negociación y/o resistencia que se producen en espacios aparentemente no funcionales a ciertos sectores. Se espera que ciertos agrupamientos sociales se ajusten a

11 La villa 31 se ubica en una zona estratégica de Buenos Aires. Emplazada en la zona norte, a metros del Sheraton Hotel, de la Avenida del Libertador (caracterizada por ser una arteria ligada a pobladores de alto poder adquisitivo) y de las estaciones de trenes y de la terminal de micros, resulta desde hace años un problema para el gobierno local. La villa, sin embargo, es la representación popular por excelencia de la "cultura villera", a través de la cual es posible pensar sobre otras villas menos visibles de la ciudad. Esta villa cuenta con un capital simbólico propio: allí vivió el Padre Mugica, famoso y emblemático de la década de los '70, de hecho sus restos descansan en el mismo espacio. Asimismo, desde dicha villa se organizó el contundente movimiento de villeros que con fuerza resistió las topadoras que pasaron sobre otros asentamientos en la etapa de la última dictadura militar. Desde el advenimiento de la democracia, simultáneamente a su repoblamiento y crecimiento, los diferentes gobiernos intentaron desalojarla. Y en el mismo sentido, diversos expertos en política urbana han intentado encontrar soluciones sin desalojo. Los nuevos colores impuestos a sus casas, así como las expresiones culturales que se han vigorizado desde la cultura de los migrantes que allí viven (particularmente bolivianos), hablan de la funcionalidad con que se constituyen en torno de procesos que apelan a la recualificación cultural. 
un territorio (barrio o asentamiento) definido desde su carácter socio-cultural. De allí, que determinadas situaciones, como la inserción conflictiva de un piquetero ${ }^{12}$ en los espacios recualificados de Puerto Madero, deben invisibilizarse con extrema contundencia. "Afean el lugar. No respetan el estilo inglés de las construcciones y reducen el valor patrimonial" (Testimonio de la Corporación Puerto Madero en referencia a Raúl Castells - 2006), fue la inmediata expresión que vertieron los miembros de la Corporación ${ }^{13}$. El piquetero no entraba en la paleta de colores de la diversidad cultural permitida para los espacios recualificados. El piquetero convocó a una mirada provocadora de la diferencia: no a la colorida diversidad exotizada, sino a la deslucida diferencia de la pobreza. Su visibilidad extremó un posible "indice de tolerancia" respecto de lo potencialmente tolerable o no (BERNAND, 1994). Castells y sus piqueteros son advertidos cuando más se distinguen del patrimonio cultural "inglés" expresado en las construcciones reconstruidas, situación que los condena aún más en su segregacionismo.

Para intentar una comprensión más acabada y más/menos discutida de la relación entre territorioy diversidad cultural resultainteresanteobservar algunos barrios vinculados a la misma. Así, en los últimos años y por efecto de la revalorización de la diversidad como categoría espacial y cultural, en la ciudad de Buenos Aires se ha fortalecido la visibilidad de ciertos "barrios étnicos". En un escenario de recusación de la culturalización/ etnización de la cuestión social (la pobreza en particular), simultáneamente en que los territorios y los pobladores migrantes de esos barrios son visibilizados positivamente en su diversidad cultural, el territorio parece convertirse en una variable de ajuste a favor de la diversidad y de su gestión (GIBAND, 2011). En un texto reciente, nos preguntábamos como entender los procesos paradójicos ligados a la emergencia de "barrios étnicos" en un contexto de relevancia adquirida por los movimientos migratorios transnacionales. Al mismo tiempo en que señalábamos la inasibilidad de dichos movimientos frente a la cristalización y estabilización de las marcas culturales inscriptas y visibilizadas en dichos barrios (LACARRIEU; MERA, 2012). Sin embargo, dichas marcas no constituyen más que una lectura "inventada" de un relato fragmentario sobre la ciudad, donde se enfatiza la idea del "mosaico" ya sea en forma positiva o negativa. El "barrio Charrúa" en Nueva Pompeya -así llamado debido a su origen boliviano-, el "barrio coreano" en Floresta - llamado Baekku- y el "barrio chino" en el barrio de Belgrano, son ejemplos prototípicos de esa construcción. Sin embargo, cada uno de ellos ofrece posibilidades de discusión sobre la territorialidad y diversidad encapsulada. Los tres han sido estudiados por los académicos, pero sobre todo son tratados desde las políticas públicas como territorios fronterizados y receptáculos donde solo reside un tipo de habitante-migrante

12 Los piqueteros son actores sociales que emergen como producto del desempleo y la crisis socio-económica. Diversos movimientos surgidos en aquel momento respondían a dichas características y ocuparon los espacios públicos de la ciudad en pos de reclamos socio-económicos. Los piqueteros, además, se identificaron con ciertos rasgos corporales (algunos llevan pañuelos en sus caras, palos en sus manos) y prácticas que suelen observarse como violentas.

13 Raúl Castells negoció con un miembro de la Corporación la posibilidad de instalar un kiosko/comedor popular en medio de los espacios recualificados de Puerto Madero. Su incorporación, aunque en el espacio público, se hizo visible para los restaurantes y edificios revitalizados de la zona y puso en discusión quien o quienes merecen circular, instalarse, residir, comerciar en este espacio. 
que, al mismo tiempo, forma parte de agrupamientos encriptados en una determinada territorialidad a contramano de los nuevos paradigmas de la movilidad - Tarrius (2000) propone dentro de uno de esos paradigmas la perspectiva del "territorio circulatorio"según la cual los espacios son aprehendidos - siguiendo a Mera (LACARRIEU; MERA, 2012), las nuevas perspectivas colocan el acento en el par movilidad/alteridad dejando atrás enfoques y lecturas de la realidad asociadas a la integración-identidad-. El énfasis puesto en el "enclave étnico" resta importancia a esos procesos de movilidad y circulación, pero también de interacciones, negociaciones y/o disputas que involucran no solo al grupo en cuestión en su territorio, sino a otros territorios y otros grupos.

El Barrio Charrúa es el producto de un proceso extenso de instalación boliviana que, sin embargo, hoy sería impensable sin otro tipo de agrupamientos sociales y sobre todo sin considerar nuevas interacciones que exceden el barrio. Es cierto que la Fiesta de la Virgen de Copacabana que más trascendencia posee en la ciudad se desarrolla en Charrúa, no obstante, la misma es el resultado de intercambios e interacciones que se procesan entre quienes habitan el barrio y muchos otros bolivianos que llegan al barrio para la fiesta desde otros espacios de la ciudad (incluso del Conurbano Bonaerense). Es decir que los primeros asentamientos de bolivianos en dicho barrio permitieron condensar y concentrar patrones de usos y apropiaciones del espacio específicos, valores y reglas de comportamiento, símbolos y prácticas hoy definidas como "bolivianas", más allá de que quienes las despliegan sean efectivamente bolivianos. Charrúa sirve a los efectos de estereotipar un tipo de cultura y de poblador y ha contribuido en su discriminación afirmativa y positiva, simultáneamente en que desde la misma se ha producido estigmatización -cuando los jóvenes, por ejemplo, son convocados por el gobierno local a realizar tareas culturales dentro de ese espacio que remitan y redunden en características andinas, en suma bolivianas de acuerdo a lo que se considera como tal en Buenos Aires, ellos reniegan de esa adscripción, no solo eludiendo la actividad, sino procurando ser identificados como "porteños" antes que bolivianos, para lo cual se vuelve necesario des-identificar a Charrúa en el mayor grado de sus posibilidades de "lo boliviano" -. Sin embargo, Charrúa y sobre todo la fiesta mencionada, sirven a los fines de negociar otros lugares de la bolivianidad en la ciudad: desde Charrúa (aunque quienes negocian no siempre viven en el barrio) se producen procesos de negociación con el poder público, por ejemplo, que acaban visibilizando a los bolivianos en el centro de la ciudad y en diferentes eventos en los que se autoriza y se pone color a la diversidad cultural - por ejemplo, durante la celebración del Bicentenario los bolivianos marcados por su etnicidad fueron parte del Desfile de la Integración junto a comunidades de migrantes legitimadas por otros valores, o bien participan del Programa Buenos Aires Celebra que organiza el gobierno local, llegando hasta las Avenidas 9 de Julio y de Mayo. Es decir que Charrúa no es solo un enclave étnico aislado entre otros enclaves en el conjunto de la ciudad, sino el resultado complejo y conflictivo de procesos de intercambios, interacciones, negociaciones y/o disputas que exceden al "micro-territorio" del barrio, que lo vinculan con otros 
espacios y grupos, y desde y hacia donde se producen estereotipos, estigmatizaciones pero también des-estigmatizaciones y exhibiciones revalorizadas de la diferencia cultural. Aunque desde otra perspectiva, algo similar ocurre con el "Barrio Chino". Como otros chinatown instalados en otras ciudades del mundo - del mundo occidental y oriental, este barrio es en principio una cuasi réplica de un modelo socio-cultural asociado a lo esperable de "lo chino". Es decir que el "barrio chino" en Buenos Aires es en primera instancia un espacio transnacionalizado resultado de ese "territorio circulatorio" del que habla Tarrius. Pero visualizado más allá de su representación visual y discursiva, es también el producto de una serie de emprendimientos llevados adelante por grupos chinos y taiwaneses, con frecuencia en connivencia con el gobierno local, que no residen en el mismo barrio y que sí han negociado su fabricación a fin de resistir una mejor imagen de la cultura china en las poblaciones no chinas. La disputa recreada en torno del Arco Chino - referente simbólico y visual de cualquier chinatown que precisa de su delimitación material y simbólica, disputa promovida desde los habitantes del barrio que no son chinos y que se vieron "invadidos" por la condensación simbólica y la extrema visibilidad de esta cultura; es un buen ejemplo de cómo la idea de enclave es discutida y discutible. En este caso, el "barrio chino" negociado desde población migrante que no vive allí con residentes no chinos, además de producto de procesos de interacción e intercambios que circulan - van y vienen entre el barrio y otros espacios de la ciudad en que los chinos residen, comercian etc., se constituye en una figura emblemática y atractiva, des-conflictivizada en tanto representación sobre-expuesta en determinados días (los fines de semana o cuando se celebra el Año Nuevo Chino), pero problematizada en la vida cotidiana y el tiempo ordinario en que los residentes circulan, viven, entran y salen del mismo. Como en el caso de Charrúa, aunque desde otro lugar, el "barrio chino" ha servido a los fines de etnizar/culturizar una nueva población, en principio "acusada material y simbólicamente" debido a prácticas y actividades vistas como indeseables por la población local. Indudablemente los dos casos deberían leerse en diferentes sentidos, debido a que los bolivianos deben producirse étnica/culturalmente en términos de su propia condición social - la pobreza con que se los identifica, mientras que los chinos deben hacerlo en clave de des-estigmatización de una cultura no solo extraña, sino además negativa para la perspectiva local - su condición socio-económica no se encuadra en la pobreza, en general todo lo contrario.

La extrema visibilidad de Charrúa o del "barrio chino" contrasta con la extrema y contundente invisibilidad en que se ha producido el "barrio coreano", no solo porque se ha construido en la periferia de la ciudad - pues Charrúa también se encuentra emplazado en una zona poco atractiva, casi desconocida y poco transitada por los "porteños", sino también porque la agregación coreana en un territorio específico parece remitir en mayor grado a esa idea de "aislamiento" y estabilidad con que suelen leerse los "enclaves". Los "umbrales de tolerancia" ligados a determinados grupos sociales son construidos en torno de negociaciones y/o procesos de resistencia que tanto pueden involucran otros actores sociales - como hemos visto en los casos mencionados - como solamente a quienes 
deciden constituirse como agrupamiento social y territorial aparentemente aislado del resto de la población.

Efectivamente, retomando a Mera (LACARRIEU; MERA, 2012), “los migrantes se asientan en el espacio urbano e impactan en él, estableciendo nuevas jerarquías sociales, redefiniendo su espacio social de pertenencia desde las nuevas territorialidades, pero también interviniendo en las formas de nombrar la diversidad en las sociedades locales, Los barrios migrantes ponen de relieve el territorio como entidad simbólica, constituida por las circulaciones espaciales y temporales en tanto disputas de poder". Es decir, disputas por el territorio, particularmente por los usos y apropiaciones territoriales que, sin embargo, se construyen negociando estéticas, patrones de convivencia, relaciones sociales de intercambio e interacción con otros territorios y otros grupos sociales, incluso de la misma pertenencia étnica.

Desde las situaciones y procesos empíricos analizados hasta aquí cabe interrogarse: ¿estamos frentea problemas ligados al territorio en tanto receptáculos o se trata de un debate que debiera darse en torno de la diferencia-igualdad/desigualdad? ¿Hasta donde los conflictos urbanos contemporáneos se definen por la fragmentación "micro-territorial" del enclave o por la diversidad cultural en tanto valor "multicultural"? Estas son inquietudes que giran en torno de ciertas cuestiones clásicas de lo urbano que regresan, aunque desde otras perspectivas. No obstante, como numerosos expertos desarrollan (DONZELOT, 2004; GIBAND, 2011), son asuntos hoy leídos desde una visión territorialista/espacialista antes que social. Giband (Op.cit.:12, n/traducción) señala que el debate se instala entre dos cuestiones: una, ligada al "vivir juntos" en relación a la "igualdad" ("notablemente territorial") pero sin etnicidad; otra, vinculada a la etnicidad como valor equivalente de la igualdad, donde "se sobrevalora el derecho a la diferencia y el entre-sí" siempre sobre "un territorio que es el receptáculo". Y agrega que "el deslizamiento se opera desde una categorización social de la diversidad [hacia] una categorización espacial", es decir observando la diversidad como "una categoría espacial reveladora de un anclaje territorial de grupos múltiples que son objeto de los efectos de discriminaciones". Sin embargo, el mismo autor reenvía a cierto debate, en el que de acuerdo a su perspectiva, esta forma de entender hoy la diversidad es un tema de retórica ligado a los discursos y acciones de las políticas públicas donde "la diversidad funciona como una categorización implícita de lo espacial que determina... [dichas] políticas públicas territoriales y las condiciones de la participación o de la movilización de los actores sobre la escena política urbana". En una lógica afín - aunque no idéntica - Borja y Castells (1992) hablan de patrones de segregación urbana fundados en "concentraciones desproporcionadas de minorías étnicas en determinadas zonas urbanas", por un lado resultado de políticas de vivienda que operan sobre el espacio y el agrupamiento afirmativo, aunque negativo, de ciertos grupos identificados por un carácter, exclusivamente cultural, homogéneo, por el otro, según los mismos autores, producto de reacciones defensivas de auto-ayuda y auto-protección desarrolladas por dichos grupos. En cualquiera de los dos casos, los autores refieren a la implantación de "micro-territorios" y de "minorías" que favorecen 
procesos de segregación, estrechamente asociados a la idea de la fragmentación urbana. Nuevamente, por este camino, se pierden los procesos de diferencia cultural-desigualdad social, enfatizándose una lectura de la realidad urbana desde operaciones "micro-quirúrgicas" del territorio o desde un análisis de la diversidad como categoría espacial.

En este sentido, es que quisiéramos, en esta última parte de este tópico, focalizar en los procesos de negociación/resistencia/disputa que cierto movimiento de afrodescendientes ha puesto en juego en el centro histórico recualificado de Buenos Aires. Como hemos visto, la creación de "paisajes" supone la producción de un tipo de espacio en el que se subsumen arreglos espaciales, sociales y culturales y eliminan "contra-usos" (PROENCA LEITE, 2009), pero sobre todo procesos de negociación y/o disputa en relación al mismo. El movimiento con el que iniciamos este tópico es paradigmático en ese sentido. La reconstrucción de un recorrido espacial en relación al cual se desarrollan no solo las llamadas de tambores y el candombe como expresiones culturales propias del grupo en cuestión, supone además una disputa por el lugar (no solo del territorio en cuanto espacio) constituido histórica, social, cultural, urbanística y políticamente.

El movimiento afrocultural hasta hace unos años poseía un centro cultural en el barrio de Constitución, próximo geográficamente y distante social y culturalmente del centro histórico de la ciudad. En tanto dicho local no pertenecía al movimiento, en determinado momento el propietario solicitó su salida y los afrodescendientes iniciaron un reclamo ante la Legislatura de la ciudad de Buenos Aires y ante el Gobierno de la Ciudad, en pos de obtener la radicación. Con el objetivo de reclamar reinventaron un relato acerca de sí mismos y el lugar: plantearon que se trataba del "ultimo quilombo urbano", por ende que ameritaba no perder el "territorio negro" que quedaba en la ciudad, enfatizando en la identidad negra en una Buenos Aires que tendió a blanquear su población. Su reclamo incorporó incluso la reivindicación patrimonial del quilombo y las expresiones culturales que ellos desarrollan. El reclamo originó una disputa por el "lugar" (el centro histórico no solo en términos de espacio territorial) que involucró a varios actores. Ya que no pudo radicarse a los afro en el viejo local de Constitución, el gobierno local ofreció trasladarlos al Espacio Cultural Defensa (centro cultural bajo la órbita del gobierno) existente en pleno corazón de San Telmo. Dicho traslado fue conflictivo, en la medida en que el centro cultural ya estaba en uso por parte de vecinos de San Telmo y las actividades fuertemente centradas en el tango. Algunas reuniones previas a la instalación afro preanunciaron una disputa que continuaría con posterioridad: en una de ellas, los vecinos plantearon que si los afro querían vivienda - como necesidad insatisfecha y por ser pobres - ellos los apoyarían en su reclamo, pero que si el mismo era una demanda cultural, no serían acompañados debido a que culturalmente el espacio era de ellos. Dicha controversia dio lugar a un amparo judicial que aún continúa, más allá de que los afro se trasladaron y al día de hoy se han hecho cargo del centro cultural.

Pero, en lo que aquí nos interesa destacar, parece bien interesante que el movimiento afrocultural decidió dar una disputa por el territorio en tanto lugar, con y más allá del centro cultural. Si observamos el siguiente testimonio, queda claro que 
ellos no solo reclaman una "cultura-identidad", o un "patrimonio", o incluso un espacio cultural donde desarrollar sus actividades, sino también un lugar-territorio con todas las implicancias que ello supone. Desde su perspectiva: "El lugar digamos la zona de San Telmo lo que significa para nosotros más o menos allí quedó reflejado, de porqué ya estando nuestros ancestros acá anteriormente, bueno estamos cerca del río también. En este lugar en particular más que nada es el espacio donde estamos preservando la cultura. Puede ser, ahora estamos acá como estuvimos en Herrera y podemos estar dentro de lo que es la zona de San Telmo, a lo mejor si nos quedamos acá en este lugar, bienvenido sea pero que sea dentro de los límites donde nosotros creemos que está parte de nuestro pasado, que está nuestro presente y futuro. Para la pregunta que hizo la señora sobre por qué es importante este espacio para nosotros. Es importante porque este espacio es, hablo del espacio me refiero al movimiento, a la asociación porque el espacio es circunstancial, el espacio no me va hacer pensar, no me va generar conciencia pero este espacio es importante porque es una escuela, no es como la universidad a donde usted va a aprender derecho $o$ lo que quiera aprender, esta es nuestra universidad, nosotros vamos a aprender de nuestra cultura, de formarnos sobre nuestra identidad, recuperarnos de nuestra identidad, no?... La casa tiene que estar, es muy importante, que esté la casa pero más que la casa, es ese espíritu no? esa memoria. Esa memoria, eso, la casa es circunstancia pero es necesaria. Este y el testimonio con el cual comenzamos este tópico da cuenta de la complejidad de la disputa en un espacio en el que el poder público y privado han intentado resolver una "paisaje cultural" en el sentido estético ya planteado. La disputa por el territorio retoma viejas hostilidades sufridas por los negros en San Telmo: durante años y hasta el presente, en ciertas ocasiones, vecinos y policías acusaron y aún acusan a ellos de generar caos y desorden debido a que templan tambores con fuego en las calles y a que hacen ruido cuando desarrollan las llamadas. De allí, que en los últimos años han construido un relato, pero también prácticas, desde los cuales se resalta la relevancia del territorio marcado por la confluencia de factores históricos, culturales y sociales, con contundente objetivo político. Ellos, en la disputa, producen esa matriz territorial, centralmente, a partir de la memoria histórica, por un lado, y por el otro, desde la constitución de la comunidad y la centralidad del candombe como expresión crucial de esa comunidad. Es decir, en primera instancia la Plaza Dorrego (considerada el centro del centro histórico) es observada por ellos como el lugar de subasta de esclavos, es decir de sus ancestros que, por ende, consideran debe volver a visibilizarse en relación a la negritud -no solo en relación a los bares, la feria de antigüedades y el turismo- a través del candombe y las llamadas. Ellos dicen: “....es un lugar que está ubicado estratégicamente para nosotros poder dar visibilidad a lo que no se ve, Entonces, este lugar está ubicado estratégicamente para dar visibilidad a todas esas, a toda esa comunidad, a todo ese potencial que está ahí y no es tan escuchado....". La disputa no es solo por el territorio y la plaza, sino sobre todo por la visibilidad social, cultural y política de los negros. La plaza así es convertida en el centro de la memoria, a la cual se llega mediante un recorrido que ellos mismos han producido como el recorrido histórico y vinculado a la memoria de los ancestros. Es de destacar que algunas de las otras agrupaciones negras que también disputan territorialidad e identidad, remarcan que el centro neurálgico 
de lo afro en Buenos Aires se ubica en el Parque Lezama (lugar donde culminan las llamadas del movimiento afrocultural, pero que para otros grupos es el inicio o lugar de transmisión de los saberes y prácticas). Entre la Plaza Dorrego y el Parque Lezama indistintamente inicio o final de las llamadas- se produce un recorrido espacial marcado por la memoria, desde el cual se promueve una disputa por el "lugar" de los negros, no solo en San Telmo, sino incluso en la sociedad de la ciudad ${ }^{14}$.

Por el otro, el lugar se disputa como "comunidad" promoviendo efectos similares en cuanto a la visibilidad de los negros. Pero en este caso resulta sumamente interesante como el espacio en tanto tal, deja de tener relevancia para convertirse en un recurso que se constituye desde el conflicto y la disputa por la presencia/existencia de los negros. Ellos dicen que el espacio no se define por el local en el que desarrollan sus actividades -puede estar en Constitución o en San Telmo-, sino por el "lugar" en tanto confluencia de elementos que hacen a la "comunidad" tal como ellos la imaginan y practican. Así, dicen que el "lugar" se define en "puntos de encuentro" manifiestos en el territorio pero definidos por el candombe, el tambor y obviamente como ya vimos el recorrido y la Plaza Dorrego (las llamadas salen de allí, donde se templan los tambores, y toman un recorrido de calles que ellos han definido como característicos de su comunidad, hasta el Parque Lezama en el casi fin del centro histórico). La resistencia que según ellos dieron por su cultura desde el "conventillo" donde vivían, se veían, compartían y no estaban dispersos en otros tiempos, y desde la práctica del tambor, debe ser reavivada con la generación de otros "puntos de encuentro" vinculados a lo espacial, sin embargo, en pos de una disputa por la visibilidad.

La tensión que establecen con el gobierno local, al plantear dos recorridos diferentes y desde esa diferenciación marcar la legitimidad del recorrido construido desde el movimiento en cuestión -como hemos visto otras agrupaciones disputan a su vez este territorio, mediante la puesta en escena de otras territorialidades y desde allí la visibilidad de lo negro-, es parte de una disputa por el centro histórico, y sobre todo por el merecimiento del lugar. La equivalencia que ellos hacen con la ESMA (Escuela de Mecánica de la Armada, ex centro clandestino de detención durante la última dictadura, hoy Museo de la Memoria) cuando dicen que “...para nosotros esta zona de San Telmo es el sitio de la memoria, la memoria de los ancestros, ese sería como si lo queremos referenciar porque necesitamos esa memoria, el tema de tocar los tambores tiene que ver con esa memoria ancestral"; es una manifestación de la trascendencia de esa disputa en torno de la legitimidad dada a la memoria.

14 Recientemente se realizó la Asamblea Nacional de los Afrodescendientes en el centro histórico de la ciudad. Resulta de interés resaltar que la misma se desarrolló con agrupaciones de todo el país, entre el Centro Cultural de la calle Defensa y el Museo Histórico Nacional que se encuentra ubicado en el Parque Lezama y cuya entrada da a la calle Defensa. Si bien el Museo "guarda" relatos históricos oficiales de tinte conservador -por ejemplo cuadros con pinturas en las que se resaltan hechos militares como el de la "Conquista del Desierto" (fines del siglo XIX), a partir del cual se exterminó una proporción importante de indios e incluso los negros fueron exterminados y que como puede observarse en uno de ellos, tanto unos como otros aparecen relegados y a un costado de la escena-, el mismo director y la secretaría de cultura junto a otras instituciones nacionales dieron el espacio para la Asamblea. Durante el evento, el Museo en continuidad con el Parque Lezama se convirtieron en lugares desde los cuales se disputó el espacio de lo afro, aunque no solo en cuanto territorio, sino sobre todo en cuanto presencia histórica y contemporánea. 
Las disputas por el lugar, en ciertas ocasiones, no son necesariamente producidas en relación a procesos de tensión. Los grupos afrodescendientes pueden volverse "funcionales" al "paisaje cultural" del centro histórico, cuando las prácticas desarrolladas exotizan el mismo recorrido $u$ otros, vistos como necesarios a fin de la visibilización y expansión de la "cultura negra" - o mismo puede suceder con otros grupos sociales.

De allí, que tanto los procesos de disputas y/o de negociaciones producen y hacen territorialidad en clave espacial, social, cultural y política. Son procesos que cuestionan el sentido fragmentario de la ciudad y que por el contrario pueden asimilarse a las nuevas "políticas de lugares" postuladas por Manuel Delgado (1998).

\section{TERRITORIALIDADES/SOCIABILIDADES EXPLÍCITAS/IMPLÍCITAS ENTRE NUEVAS FORMAS DE PRODUCIR "LUGARES"}

Hace unos años, un tiempo después de que se produjera la crisis socio-económica en Argentina que impactó con contundencia en la ciudad de Buenos Aires, publicamos un artículo en el que planteábamos que la misma se había reconstruido en base a "micro-recorridos de la crisis" que enfrentaban los viejos "micro-recorridos del progreso" (LACARRIEU, 2005). En aquel texto hacíamos referencia a situaciones y procesos que habían entrado en disputa en el mismo centro histórico con el objeto de reescribir relatos y narrativas en pos de formar parte de un "pasado canónico" (BRUNNER, citado en MORAWSKA-VIANNA, 2007, p.161) que permitiera re-estructurar no solo el lugar en cuanto espacio urbano, sino sobre todo el lugar en cuanto ámbito de visibilidad de otras y diferentes culturas públicas resistiendo la legitimidad de un solo relato. Ese fue el antecedente de los procesos comentados previamente, cuando por ejemplo, una Asamblea Popular nacida al calor de la crisis, realizó varios actos de resistencia respecto de los "vecinos notables y patrimonialistas". La presencia de una murga creada por la Asamblea fue, por caso, una forma de poner en tensión la estructura coherente dada al espacio en tanto "paisaje cultural": la puesta en juego de un relato en el que los "negritos" fueron visibilizados como los "herederos naturales" del lugar, tensionó no solo la historia del pasado colonial esclavista, sino también la historia contemporánea, explicitando una continuidad entre los esclavos negros y los "negritos" que hoy habitan las "casas tomadas" que, aunque no afros, serían asimilables a aquellos, y en ese sentido planteados como los "desheredados" de la ciudad blanca y del espacio fundacional de la misma.

A distancia de aquel análisis, consideramos que no se produjeron "micro-recorridos" caracterizados por la particularidad de la crisis o la especificidad del progreso. Así como, de acuerdo a los nuevos ejemplos sobre los que focalizamos, no se trata de pequeños fragmentos o "micro-territorialidades" desde los cuales se deducen "microinteracciones" sociales y culturales que no llevarían más que a "guettos" o "enclaves" urbanos. Los lugares tal como fueron planteados en este texto, son el producto de espacios de movilidad y circulación, entre los cuales se producen diálogos - no monólogos sociales, identitarios, culturales con el espacio, los que dan espacio (valga la redundancia) 
a procesos de negociación, pero también a luchas por el reconocimiento de los diferentes grupos y sujetos, obviamente también productores de ese espacio. Con esto queremos decir que la territorialidad es solo una condición más entre otras y no un determinante de los procesos mencionados. Esta forma de mirar la "nueva cuestión urbana" no implica eludir los procesos de segregación promovidos entre negociaciones, disputas y luchas por el lugar. Entre procesos de negociación de estéticas, diseños, patrones de convivencia, relatos y prácticas y luchas por el reconocimiento socio-político, la segregación tiende a profundizarse por efecto de las desigualdades que, sin duda, trascienden las diferencias sociales y culturales. No basta con negociar estéticas exotizadas - mediante la puesta en escena de existencias étnicas, plasmada en discriminaciones territoriales positivas, aunque tampoco basta con producir disputas por el reconocimiento para superar esos procesos de segregación desigualitaria. Sin embargo, son procesos que resultan suficientes para repensar las ideas de anclaje territorial o las de la sociabilidad e identidad condicionadas por la localización territorial.

\section{REFERENCIAS}

AGIER, Michel. L'invention de la ville : banlieus, townships, invasions et favelas. Francia: Éditions des archives contemporaines, 1999.

AMENDOLA, Giandomenico. La ciudad posmoderna: magia y miedo de la metrópolis contemporánea. Traducción de Marisa García Vergaray y Paolo Sustersic. Madrid: Celeste Ediciones. 2000.

APPADURAI, Arjun. O medo ao pequeno número: ensaio sobre a geografia da raiva. São Paulo: Iluminuras, Observatório Itaú Cultural, 2009. Traducción Ana Goldberger.

BAUTES, Nicolás. Ativismo Urbano, Estetização resistente e economia cultural, no Rio de Janeiro. In: Cidade e sustentabilidade: mecanismos de controle e resistência. Rio de Janeiro: Terra Vermelha Editora, 2010.

BENIT, C. ; DIDIER, S. ; DORIER-APPRILL, E.; GERVAIS-LAMBONY, P. Fragmentations. In: DORIERAPPRILL, E. ; GERVAIS-LAMBONY, P. (Coord.). Vies citadines. Belin, Paris: 2007.

BERNAND, Carmen. Ségrégation et anthropologie, anthropologie de la ségrégation. Quelques éléments de réflexion. In : BERNAND, Carmen (Ed.). La ségrégation dans la ville. Paris: L'Harmattan, 1994.

BORJA , Jordi; CASTELLS, Manuel. La Ciudad Multicultural. In: BORJA, Jordi; CASTELLS, Manuel. Local y global: la gestión de las ciudades en la era de la información. Madrid/España: Editorial Taurus, 1992.

BORJA, J.; MUXI, Z. El espacio público: ciudad y ciudadanía. Diputació de Barcelona: Electa, 2003.

BOVONE, Laura. Os novos intermediários culturais. In: FORTUNA, Carlos (Org.). Cidade, cultura e globalização: ensaios de sociologia. Oeiras: Celta Editora, 1997.

CALDEIRA, Teresa. Espacio, segregación y arte urbano en el Brasil. Buenos Aires: Katz, 2010.

COELHO, Teixeira. A cultura e seu contrário. São Paulo: Iluminuras, Observatório Itaú Cultural, 2008.

DELGADO, Manuel. Las estrategias de memoria y olvido en la construcción de la identidad urbana: el caso de Barcelona. En: HERRERA GÓMEZ, D. (Coord.). Ciudad y Cultura. Memoria, identidad y comunicación. Antioquía: Ediciones Universidad de Antioquía, 1998.

DONZELOT, J. La ville a trois vitesses: relègation, pèriurbanisation, gentrification. Revue Esprit, La Ville a trois vitesses, n.303, mars-avril 2004, Francia. 
FLORIDA, Richard. La Clase Creativa. La transformación de la cultura del trabajo y el ocio en el siglo XXI. Madrid: Espasa Libros, 2010. Traducción de Montserrat Asensio (del original The rise of the Creativa Class, Basic Books, NY, 2002).

GIBAND, David. Les villes de la diversité : territoires du vivre ensemble. Anthropos, Francia, 2011.

GIGLIA, Ángela. ¿Es posible la urbanidad en las megaciudades? En: PRÉACTES DU SÉMINAIRE PRISMA, 3. Toulouse: 2000.

GRAVARI-BARBAS, María. Introduction Générale. En: GRAVARI-BARBAS, María (Coord.). Habiter le patrimoine : enjeux-approches-vécu. Rennes: Presses Universitaires de Rennes, 2005.

LACARRIEU, M. Nuevas políticas de lugares: recorridos y fronteras entre la utopía y la crisis. En: GUERRA, Max Welch (Ed.). Buenos Aires a la deriva: transformaciones urbanas recientes. Buenos Aires: Editorial Biblos, 2005.

LACARRIEU, M.; MERA, C. Design, diversity and inclusion: debates for a future view on the City: ponencia presentada. En: (Un)Anticipated Futures, Symposium 2012, Chulalongkorn University, February 16-19, Bangkok, Tailandia. 2012.

LINS RIBEIRO, Gustavo. Otras globalizaciones: procesos y agentes alter-nativos transnacionales. Série Antropologia, n. 423, Brasilia, 2006.

MASSEY, Doreen. Pelo espaço: uma política da espacialidade. Rio de Janeiro: Bertrand Brasil, 2008.

MATO, Daniel. Actores sociales trasnacionales, organizaciones indígenas, antropólogos y otros profesionales en la producción de representaciones de "cultura y desarrollo". En: MATO, Daniel (Coord.). Políticas de identidades y diferencias sociales en tiempos de globalización. Venezuela: Faces-UCV, CEAP, CDCH, 2003.

MONNET, Jérôme. O álibi do patrimonio. Crise de cidade, gestao urbana e nostalgia do passado". Revista do Patrimonio Histórico e Artístico Nacional, n. 24, 1996.

MORAWSKA-VIANNA, Anna Catarina. Em busca de narrativas densas: questões acerca de realidades narrativas, subjetividade e agencia social. Cadernos de Campo, n. 16, São Paulo, Brasil, 2007.

PROENCA LEITE, Rogério. Cidades, consumo e empobrecimento urbano no Brasil e em Portugal. Rio de Janeiro: LASA, 2009.

SANTOS, Milton. O retorno do território. En: Território. Globalização e Fragmentação. São Paulo: Hucitec, 1996.

SEGATO, Rita. Alteridades históricas/Identidades politicas: una crítica a las certezas del pluralismo global. Série Antropología, n. 234, Brasilia, 1997.

SIGNORELLI, Amália. Antropologia urbana. México: UAM-Iztapalapa, 1999.

SMITH, Neil. A gentrificacao generalizada: de uma anomalia local a "regeneracao" urbana como estratégia urbana global. En: BIDOU-ZACHARIASEN, Catherine. De volta a cidade. Dos processos de gentrificação às políticas de "revitalização" dos centros urbanos. São Paulo: Annablume Editora, 2006.

TAMASO, Izabela. A expansão do patrimônio: novos olhares sobre velhos objetos, outros desafios... Brasília: 2006. (Série Antropologia, 390).

TARRIUS, Alain. Leer, describir, reinterpretar las circulaciones migratorias: conveniencia de la noción de "Territorio circulatorio": los nuevos hábitos de la identidad. Relaciones, n. 83, v. 21, verano 2000.

TISSOT, Sylvie. De bons voisins: enquete dans um quartier de La bourgeosisie progressiste. Paris: Éditions Raisons d'Agir, 2011.

VAINER, Carlos. Pátria, empresa e mercadoria. En: ARANTES, Otília; VAINER, Carlos; MARICATO, Ermínia. A cidade do pensamento único: desmanchando consensos. Petrópolis: Editora Vozes, 2000. 
YÚDICE , George. Modelos de desarrollo cultural urbano: ¿gentrificación o urbanismo social? Revista Alteridades, v. 18, n. 36, UAM Iztapalapa/México, 2008.

ZUKIN, Sharon. Paisagens urbanas pós-modernas: mapeando cultura e poder. Revista do Patrimonio Histórico e Artístico Nacional, Rio de Janeiro, n. 24, IPHAN, 1996.

Recebido em 19/03/2012

Aceito para publicação em 12/04/2012 